\title{
ANATOMIA DOS LENHOS DE EPHEDRA TWEEDIANA, GNETUM GNEMON E WELWITSCHIA MIRABILIS (GNETIDAE) ${ }^{1}$
}

\author{
ANELISE MARTA SIEGLOCH² JOSÉ NEWTON CARDOSO MARCHIORI ${ }^{3}$
}

\section{RESUMO}

O lenho das espécies em estudo apresenta estruturas muito distintas. Ephedra tweediana tem anéis de crescimento descontínuos, vasos numerosos e de lúmens estreitos, e placas de perfuração foraminadas, com 6-20 perfurações. Gnetum gnemon identifica-se pela ausência de anéis de crescimento, pelos vasos de grandes lúmens e placas de perfuração simples, por vezes foraminadas (até 8 perfurações). Welwistchia mirabilis, por sua vez, distingue-se pelas células espiculares com cristais de oxalato de cálcio.

Palavras-chave: anatomia da madeira, Ephedra, Gimnospermas, Gnetidae, Gnetum, Welwitschia.

\section{ABSTRACT}

[Wood anatomy of Ephedra tweediana, Gnetum gnemon and Welwitschia mirabilis (Gnetidae)]. The three studied wood species present a large variation in its wood anatomical features. Ephedra tweediana shows discontinuous growth rings, numerous vessels with narrow lumens and only foraminate perforation plates (6-20 perforations). Gnetum gnemon distinguishes itself by the absence of growth rings and vessels with large lumens, with simple perforation plates, sometimes foraminate up to 8 perforations. The wood of Welwistchia mirabilis, in turn, shows spicular cells with calcium oxalate crystals.

Key words: Ephedra, Gnetidae, Gnetum, Gymnosperms, Welwitschia, wood anatomy.

\section{INTRODUÇÃO}

$\mathrm{Na}$ natureza, encontram-se cinco linhagens principais de plantas vivas com sementes: Cycadidae, Ginkgoidae, Gnetidae, Pinidae e plantas com flores (Angiospermas). As quatro primeiras compõem as Gimnospermas, por terem sementes nuas, em oposição às Angiospermas, cujas sementes estão protegidas no interior de um carpelo (Judd et al., 2009).

As Gimnospermas, com exceção das Gnetales, apresentam traqueoides no xilema; já as Angiospermas e Gnetales apresentam elementos de vaso, que são mais eficientes do que traqueoides para o transporte de água em algumas circunstâncias (Judd, 2009).

1 Recebido para publicação em 20/11/2017 e aceito para publicação em 16/02/2018.

2 Engenheira Florestal. Doutoranda do Programa de PósGraduação em Engenheira Florestal. Bolsista - CAPES. Universidade Federal de Santa Maria. Santa Maria, RS, Brasil.anesiegloch@yahoo.com.br

3 Professor Titular do Departamento de Ciências Florestais, Universidade Federal de Santa Maria. Santa Maria, RS, Brasil. marchioricfl@gmail.com
As Gnetidae têm particular importância no contexto da evolução das plantas por reunirem caracteres tanto de Gimnospermas (sementes envolvidas em um ovário), como de Angiospermas, caso de elementos de vaso no lenho, estruturas reprodutivas com aspecto de flores e dupla fertilização (Judd, 2009).

A subclasse Gnetidae compreende as ordens Ephedrales, Gnetales e Welwistchiales, com uma única família e gênero em cada ordem, as quais são muito distintas entre si sob o ponto de vista morfológico (Christenhusz et al., 2011; Judd et al., 2009).

A família Ephedraceae reúne ervas e arbustos eretos ou volúveis (raramente arvoretas), geralmente dioicos, com ramos verticilados geralmente verdes e fotossintetizantes, e folhas simples, opostas ou verticiladas, escamiformes e de margem inteira (Souza \& Lorenzi, 2012).

O gênero Ephedra, com cerca de 60 espécies, distribui-se nas regiões temperadas do mundo, com exceção da Austrália. Adaptadas a regiões extremamente áridas e ensolaradas, as espécies habitam estepes e desertos, em altitu- 
des de até 4000 m nos Andes e Himalaia (Judd et al., 2009). No Brasil, registra-se uma única espécie, Ephedra tweediana, nativa no Rio Grande do Sul (Souza \& Lorenzi, 2012).

Conhecida popularmente por "efedra" ou "trepadeira-macarrão", Ephedra tweediana é nativa na Argentina, Uruguai e sul do Brasil, chegando a ser frequente na Serra do Sudeste do Rio Grande do Sul e nos arredores de Porto Alegre (Marchiori, 2005). Trata-se de arbusto dióico, escandente e de até $6 \mathrm{~m}$ de altura, provido de folhas caducas de $5 \mathrm{~mm}$ de comprimento. Os estróbilos masculinos, globosos (cerca de 6mm), reúnem 3-7 pares de brácteas decussadas. Os femininos, pedunculados, vermelhos, carnosos e com 8-10mm de comprimento, apresentam, geralmente, duas sementes (Marchiori, 2005).

A família Gnetaceae reúne lianas lenhosas, arbustos e árvores, as quais são, geralmente, dioicas, de folhas simples, opostas, largas, comumente elípticas, e sementes envolvidas em sarcotesta carnosa (Judd et al., 2009; Souza; Lorenzi, 2012).

O gênero Gnetum compreende umas trinta espécies (principalmente lianas) de distribuição pantropical disjunta. No Brasil, encontram-se seis espécies na Amazônia: Gnetum leyboldii, G. nodiflorum, G. paniculatum, G. schwackeanum, G. urens e G. venosum (Souza; Lorenzi, 2012).

Gnetum gnemon L., conhecido por "melinjo" ou "belinjo", é planta nativa no Sudeste da Ásia e ilhas do Pacífico Ocidental, incluindo Fiji, Indonésia, Malásia, Papua Nova Guiné, Filipinas e Vanuatu. Árvore pequena (8-15 m) e de folhas verdes, opostas, inteiras e oblongas (de 10-20×4-7 cm), apresenta estróbilos masculinos pequenos, em longos pedúnculos, e estróbilos femininos carnosos, vermelho-alaranjados, de $6-10 \mathrm{~cm}$, com uma única semente (Harley; Craing, 2006).

A família Welwitschiaceae, compreende uma única espécie viva, Welwitschia mirabilis Hook. f., nativa no Sudoeste da África (Namíbia). Caracteriza-se, morfologicamente, pelo caule cur- to, maciço, com duas folhas opostas e em forma de fita, as quais, a partir da base, crescem ao longo de toda a vida da planta (Gifford; Foster, 1988). Trata-se do dito "polvo-do-deserto", nativo na região do Cabo Negro, no sudoeste da África, em área de clima extremamente árido (Rodin, 1953). De sua morfologia, destacamse, ainda, os estômatos em ambas as faces da folha e os cones femininos vermelhos, com uma única semente alada, que se dispersa pelo vento (Gifford; Foster, 1988).

Além da descrição anatômica do lenho de Ephedra tweediana, Gnetum gnemon e Welwistchia mirabilis, o presente estudo visa a reconhecer caracteres anatômicos de valor taxonômico para os táxons envolvidos.

\section{MATERIAL E MÉTODOS}

As amostras de lenho de Gnetum gnemon e Welwitschia mirabilis foram recebidas mediante permuta com o New York Botanical Garden. A de Ephedra tweediana foi coletada no Rio Grande do Sul e sua exsicata encontra-se depositada no Herbário do Departamento de Ciências Florestais da Universidade Federal de Santa Maria (HDCF) sob o número 3215.

Das amostras disponíveis, foram preparados três corpos-de-prova, orientados para a obtenção de cortes anatômicos nos planos transversal, longitudinal radial e longitudinal tangencial; de outro fragmento foram obtidos palitinhos, usados no preparo de lâminas de macerado.

Os corpos-de-prova foram fervidos em água, até a expulsão completa das partículas gasosas existentes no interior da madeira.

A microtomia foi realizada no Laboratório de Anatomia da Madeira da Universidade Federal do Paraná, utilizando-se micrótomo de deslizamento modelo Spencer (American Optical n. 860), regulado para obtenção de cortes anatômicos com espessura nominal de 16 a $20 \mu \mathrm{m}$.

Mantidos em Placa de Petri, com água, os cortes sofreram coloração com solução aquosa de "Safra-Blau", ou seja, uma mistura, em partes iguais, de Safranina 1\% e Azul-de-Astra $1 \%$. 
Após esta etapa, os cortes foram lavados em água destilada, para a extração do excesso de corante, desidratados em série alcoólica ascendente (álcool etílico 25\%, 50\%, 75\%, 90\%, 95\%, com duas passagens em álcool absoluto P.A.) e diafanizados em xilol. Na montagem de lâminas permanentes, usou-se "Entellan".

No preparo das lâminas de macerado, os palitinhos, obtidos manualmente com formão, passaram por dois banhos em solução de Jeffrey (Freund, 1970), com duração de 24 horas cada. O material dissociado foi recolhido em papel filtro (funil), colorido com Safranina 1\%, desidratado em álcool etílico conforme anteriormente descrito, e conservado em Xilol até a montagem de 6 lâminas permanentes por amostra.

A descrição baseou-se nas recomendações do IAWA Committee (Wheeler et al., 1989). No caso da percentagem dos tecidos, foram realizadas 600 determinações ao acaso, com auxílio de contador de laboratório, conforme proposto por Marchiori (1980). A abundância de poros foi obtida a partir de um quadrado de área conhecida, superposto a fotomicrografias de seções transversais da madeira.

As medições foram realizadas em microscópio Carl Zeiss, no Laboratório de Anatomia da Madeira da Universidade Federal de Santa Maria. Para cada característica quantitativa são informados os valores mínimo, médio, máximo e desvio padrão (mínimo-média-máximo, $s=$ desvio padrão). As fotomicrografias foram obtidas em aparelho Leica DM 2000, equipado com câmera digital Leica DFC 295, no Laboratório de Botânica Estrutural do Departamento de Biologia da UFSM.

\section{DESCRIÇÕES ANATÔMICAS}

As três espécies em estudo são a seguir descritas e ilustradas, por ordem alfabética de nome científico.

1 - Ephedra tweediana Fisch. \& C.A. Mey.

Anéis de crescimento: distintos, marcados por traqueoides radialmente estreitos no lenho tardio e segmentados em "degraus" des- contínuos, interrompidos por raios largos (Figura 1A,B).

Vasos: de seção poligonal $(27,5-38,5-57,5$ $(\mathrm{s}=6,9) \mu \mathrm{m})$, com abundância de $235 / \mathrm{mm}^{2}$ $(\mathrm{s}=21,4)$ e paredes relativamente finas $(1,3-3,6-$ $6,3(\mathrm{~s}=1,3) \mu \mathrm{m})$. Porosidade difusa, uniforme. Vasos solitários ou em contato parcial com outros, compondo $27 \%$ do volume da madeira (Figura 1A,B). Elementos vasculares de 650-1032$1340(\mathrm{~s}=174) \mu \mathrm{m}$ de comprimento, com placas de perfuração foraminadas, verticais, providas de 6-20 perfurações arredondadas, alternas (Figura 1D). Apêndices, espessamentos espiralados, estriações, tilos e depósitos, ausentes. Pontoações intervasculares escassas, arredondadas (10-14-15 $(\mathrm{s}=1,7) \mu \mathrm{m})$ e em arranjo unisseriado, por vezes bi ou trisseriado-alterno, com abertura circular-inclusa. (Figura 1D)

Parênquima axial: apotraqueal difuso-emagregados, por vezes paratraqueal, representando $12 \%$ do volume da madeira. Séries parenquimáticas axiais de 195-350-500 ( $\mathrm{s=96}$ ) $\mu \mathrm{m}$ de altura, geralmente com 2 ou 3 células.

Raios: com abundância de 3-6-9/mm ( $\mathrm{s}=1,3)$, ocupando $22 \%$ do volume da madeira; fracamente homogêneos, compostos por células quadradas, eretas e curto procumbentes, densamente pontoadas. Raios unisseriados e multisseriados, de 420-1287-1900 ( $\mathrm{s}=362) \mu \mathrm{m}$ de altura, com 624-39 (s=8,4) células e 10-19-37 $(\mathrm{s}=6,3) \mu \mathrm{m}$ de largura, com 2-3-6 ( $\mathrm{s=1,0)}$ células (Figura 1E,F).

Traqueoides axiais: compondo $38 \%$ do volume da madeira; de 730-1146-1450 ( $\mathrm{s=196)} \mu \mathrm{m}$ de comprimento, seção poligonal (17,5-24-30 $(\mathrm{s}=3,4) \mu \mathrm{m})$, paredes finas $(2,5-4,7-6,2(\mathrm{~s}=1,0)$ $\mu \mathrm{m})$ e com pontoações circulares (Figura 1A,B).

Outros caracteres: canais intercelulares, canais celulares, cistos glandulares, estrutura estratificada, cristais, células oleíferas, células mucilaginosas e máculas medulares, ausentes.

\section{1 - Gnetum gnemon $\mathrm{L}$.}

Anéis de crescimento: indistintos (Figura 2A,B).

Vasos: de seção poligonal (60-92-120 $(\mathrm{s}=15,4) \mu \mathrm{m})$, com abundância de $15 / \mathrm{mm}^{2}$ 


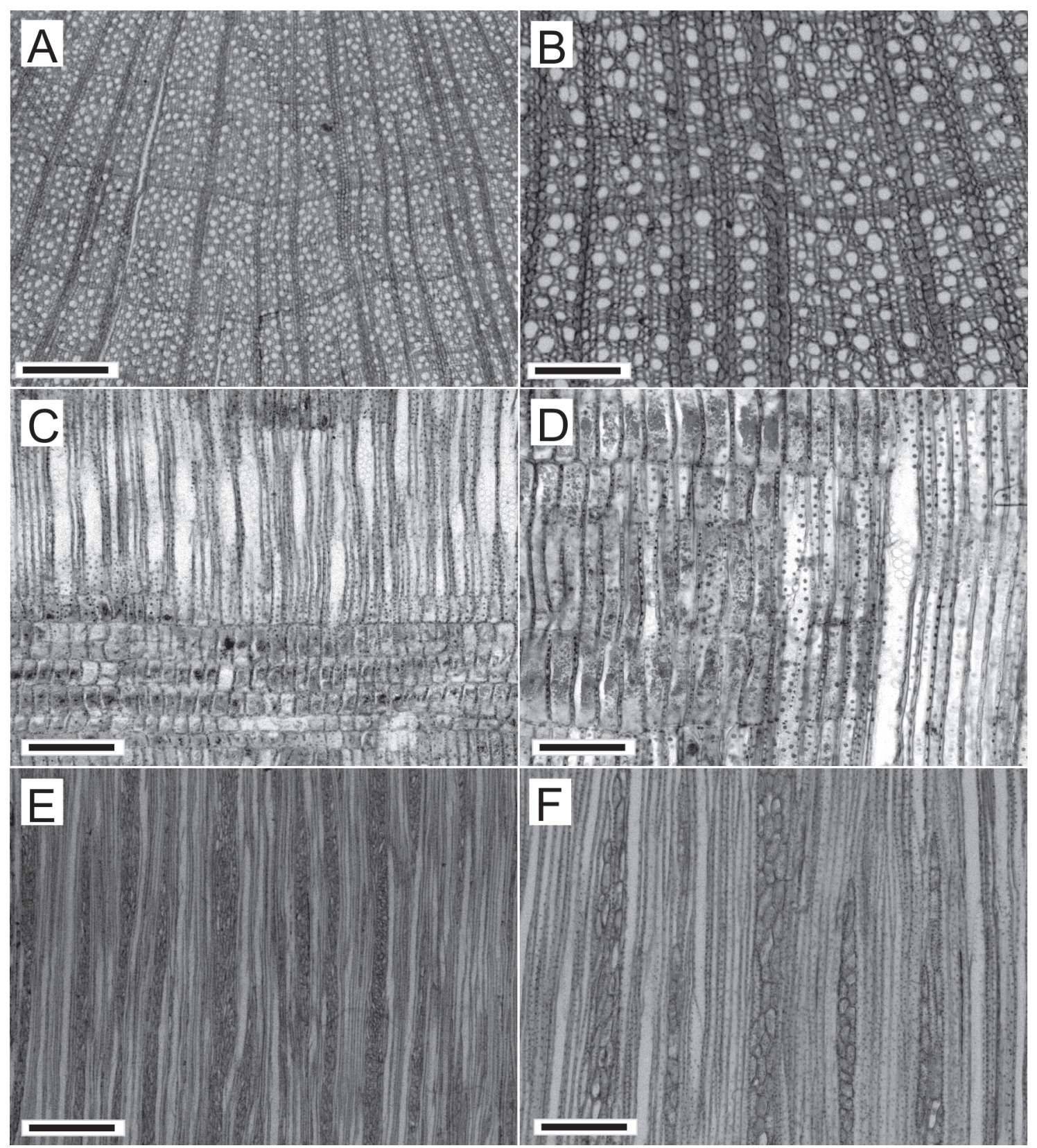

FIGURA 1 - Fotomicrografias do lenho de Ephedra tweediana. A,B - Anéis de crescimento distintos, segmentados em "degraus" entre raios largos. C,D - Raios fracamente homogêneos, campo de cruzamento com numerosas pontoações e placas de perfuração foraminadas. E,F - Raios unisseriados e multisseriados. A,B - Seção transversal. C,D - Seção radial. E,F - Seção tangencial. Escala das barras: A,E=500 $\mu \mathrm{m} ; \mathrm{B}, \mathrm{C}, \mathrm{F}=200 \mu \mathrm{m} ; \mathrm{D}=100 \mu \mathrm{m}$. 


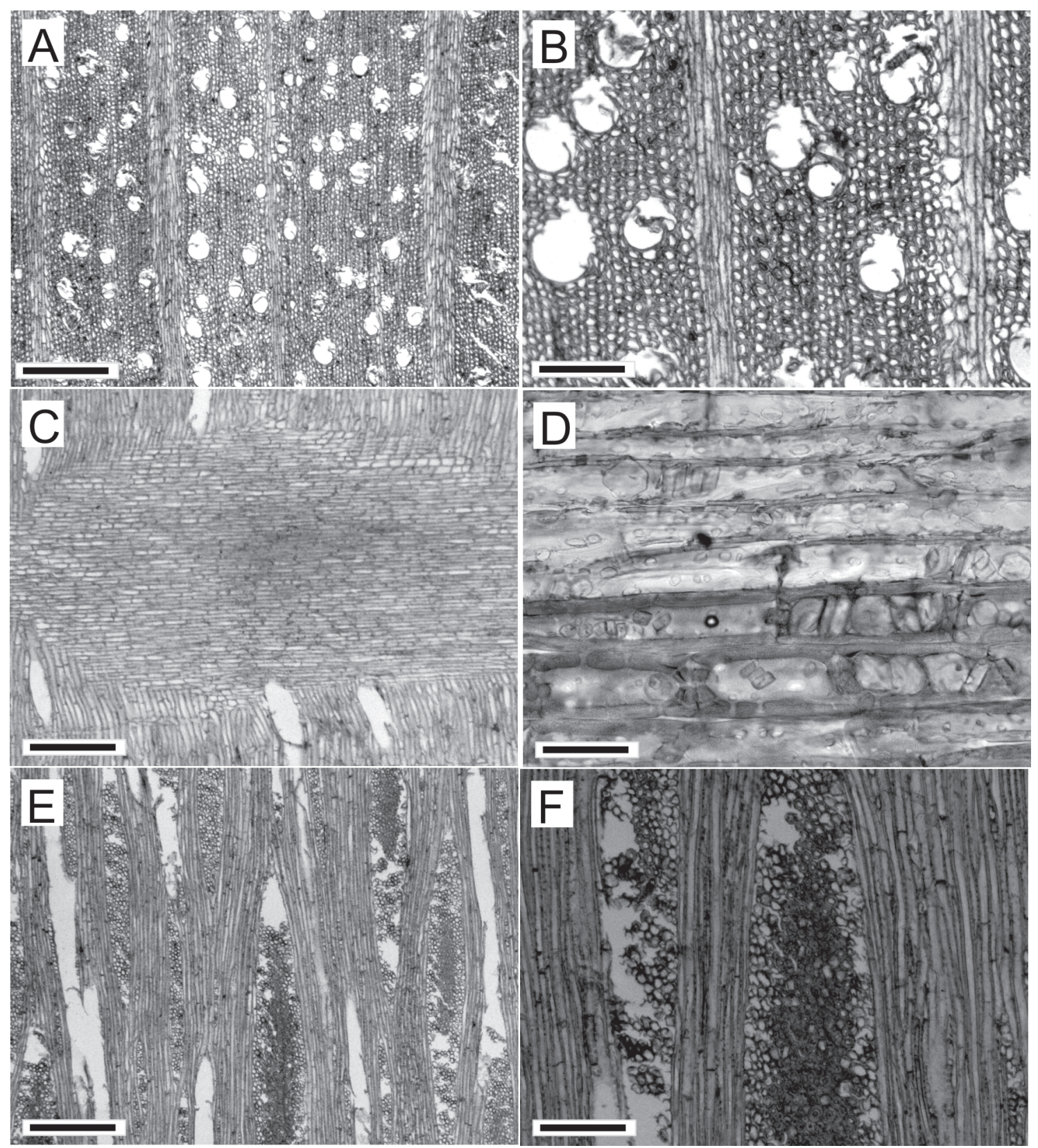

FIGURA 2 - Fotomicrografias do lenho de Gnetum gnemon. A,B - Anéis de crescimento indistintos, parênquima axial apotraqueal difuso e paratraqueal escasso. C,D - Raio fracamente homogêneo de células procumbentes, com cristais. E,F - Raios unisseriados e multisseriados. A,B - Seção transversal. C,D - Seção radial. E,F - Seção tangencial. Escala das barras: $\mathrm{A}, \mathrm{C}, \mathrm{E}=500 \mu \mathrm{m} ; \mathrm{B}, \mathrm{F}=200 \mu \mathrm{m} ; \mathrm{D}=50 \mu \mathrm{m}$. 


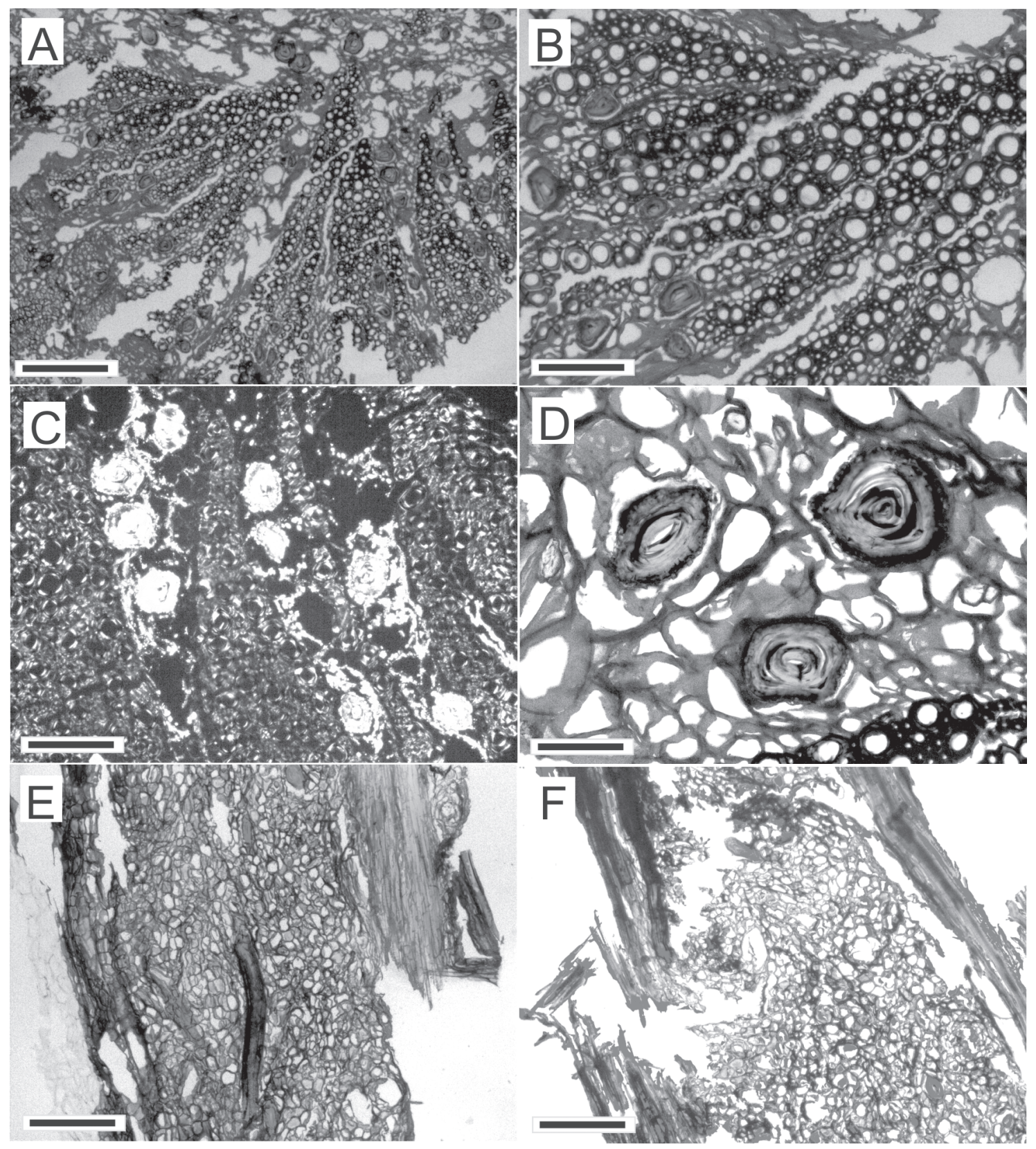

IGURA 3 - Fotomicrografias do lenho de Welwitschia mirabilis. A,B - Feixes vasculares e tecido parenquimático. C Células espiculares, com cristais de oxalato de cálcio (luz polarizada). D - Células espiculares, com cristais de oxalato de cálcio. E,F - Tecido parenquimático com ductos mucilaginosos, elementos de vasos e traqueoides. A,B,C,D - Seção transversal. E,F=Seção longitudinal. Escala das barras: A,E,F=500 $\mu \mathrm{m} ; \mathrm{B}, \mathrm{D}=200 \mu \mathrm{m} ; \mathrm{D}=100 \mu \mathrm{m}$. 
$(\mathrm{s}=3,2)$ e paredes relativamente finas $(2,5-3,9$ $6,3(\mathrm{~s}=1,2) \mu \mathrm{m})$. Porosidade difusa, uniforme. Vasos solitários ou em contato parcial com outros, ocupando $15 \%$ do volume da madeira (Figura 2A,B). Elementos vasculares de 400-1010$1300(\mathrm{~s}=247) \mu \mathrm{m}$ de comprimento, com placas de perfuração simples, menos comumente foraminadas (Figura 2A,B). Apêndices ausentes ou restritos a uma das extremidades. Espessamentos espiralados, estriações, tilos e depósitos, ausentes. Pontoações intervasculares escassas, arredondadas $(10-13-15,5(\mathrm{~s}=1,7) \mu \mathrm{m})$ e em arranjo unisseriado, por vezes bi a trisseriado-alterno, com abertura circular, inclusa.

Parênquima axial: apotraqueal difuso-emagregados, por vezes paratraqueal escasso, ocupando $10 \%$ do volume da madeira (Figura 2A,B). Células parenquimáticas axiais de 500744-110 ( $\mathrm{s=188)} \mu \mathrm{m}$ de altura, com 2-4 células por série.

Raios: fracamente homogêneos, com abundância de 2-4-6/mm (s=0,6), compondo $23 \%$ do volume da madeira; com células procumbentes, no corpo central, e, por vezes, 1 fileira de células quadradas, nas margens. Raios unisseriados de 11-21-50 $(\mathrm{s}=8,6) \mu \mathrm{m}$ de altura, com 40-76$140(\mathrm{~s}=8,6)$ células. Raios multisseriados de 260-558-1000 ( $\mathrm{s}=208) \mu \mathrm{m}$ de altura, com 63140-300 ( $\mathrm{s}=208)$ células, e 12-36-90 $(\mathrm{s}=22,3)$ $\mu \mathrm{m}$ de largura, com 2 -6-15 (s=3,5) células (Figura $2 \mathrm{E}, \mathrm{F}$ ).

Traqueoides axiais: ocupando $51 \%$ do volume da madeira; de 1130-1348-1830 ( $\mathrm{s=182}$ ) $\mu \mathrm{m}$ de comprimento, seção poligonal (25-35-50 $(\mathrm{s}=6,7) \mu \mathrm{m})$ e paredes finas $(2-6-9(\mathrm{~s}=1,9) \mu \mathrm{m})$, com pontoações circulares (Figura 2A,B).

Outros caracteres: canais intercelulares, canais celulares, cistos glandulares, estrutura estratificada, células oleíferas, células mucilaginosas e máculas medulares, ausentes. Cristais, presentes.

\section{3 - Welwitschia mirabilis Hook. $f$.}

Tecido parenquimático, predominante no xilema. Vasos circulares, distribuídos em fei- xes rodeados por traqueoides e células de parênquima (Figura 3A,B). Elementos vasculares com numerosas pontoações areoladas e em arranjo alterno, com aberturas elípticas, horizontais e placas de perfuração simples (Figura 3E,F). Parênquima com abundantes células espiculares, providas de cristais de oxalato de cálcio (Figura 3A,B,C,D). Ductos mucilaginosos, presentes no tecido fundamental (Figura 3E,F). Raios medulares, presentes.

\section{ANÁLISE DA ESTRUTURAANATÔMICA}

As três espécies descritas corroboram, em linhas gerais, as características anatômicas descritas por Greguss (1955) para as famílias e gêneros em questão.

A família Ephedraceae (Ephedra tweediana) distingue-se pelos poros solitários de contorno angular e com diâmetro gradativamente menor ao longo do anel, pelos elementos vasculares com 18-26 perfurações foraminadas (ou efedroides) por placa, organizadas em 2-3 fileiras alternas, e pelos raios de 1(4-5) células de largura, com 30-40 células de altura. As características observadas somente diferem do descrito por Greguss (1955) para Ephedraceae no tocante aos raios, que são maiores (1-6 células de largura e 6-30 células de altura), e nas perfurações, que são mais numerosas (6-20) por placa.

Para a família Gnetaceae, Greguss (1955) relaciona anéis de crescimento distintos, porosidade difusa e uniforme, placas de perfuração simples e escalariformes, raios largos e estreitos (8-10 células de largura), fusiformes em seção tangencial, com 40-100 células de altura e abundantes cristais prismáticos de oxalato de cálcio. O material examinado difere do descrito por Greguss (1955) pela ausência de anéis de crescimento distintos, pelos elementos vasculares com placas de perfuração simples e foraminadas, e por ter raios mais altos e largos (63-300 células de altura e 2-15 células de largura) do que o referido pelo anatomista húngaro.

A presente descrição de Welwitschia mirabilis (Welwitschiaceae), concorda, integral- 
mente, com o referido por Greguss (1955): anéis de crescimento indistintos, placas de perfuração simples, pontoações areoladas com abertura elíptica, horizontal e em arranjo araucarioide, e células espiculares de paredes espessas.

A anatomia do lenho, em suma, proporciona fácil segregação para as espécies descritas: Ephedra tweediana distingue-se pelos anéis de crescimento descontínuos, pelos vasos numerosos e de lúmens estreitos, pelas placas de perfuração exclusivamente foraminadas (6-20 perfurações) e pelos raios com 2-6 células de largura, compostos de células fracamente procumbentes, quadradas e eretas; Gnetum gnemon separa-se pela ausência de anéis de crescimento, pelos vasos de grandes lúmens, pelas placas de perfuração simples (por vezes foraminadas, com até 8 perfurações), e pelos raios com 2-15 células de largura, providos de cristais prismáticos, compostos de células procumbentes, no corpo central, e uma fileira marginal de células quadradas; Welwistchia mirabilis, por sua vez, identifica-se pelos vasos distribuídos em feixes, pelas placas de perfuração simples, e pelas células espiculares com cristais de oxalato de cálcio.

\section{AGRADECIMENTOS}

Os autores agradecem ao Laboratório de Botânica Estrutural do Departamento de Biologia da Universidade Federal de Santa Maria (UFSM) pelo uso dos equipamentos de fotomicrografia

\section{RERÊNCIAS BIBLIOGRÁFICAS}

CHRISTENHUSZ, M.J.M; REVEAL, J.L.; FARJON, A.; GARDNER, M.F.; MILL, R.R; CHASE M. W. A new classification and linear sequence of extant Gymnosperms. Phytotaxa, p. 55-70, 2011.

GREGUSS, P. Identification of living Gymnosperm on the basis of Xylotomy. Budapest: Akadémiai Kiadó, 1955. 263 p.

GIFFORD, E.M.; FOSTER, A.S. Comparative morphology of vascular plants. New York: W.H. Freeman (Chapter 18), 1988.

HARLEY, H.M.; CRAING, R.E. Gnetum gnemon (gnetum). Species profiles for Pacific Island Agroforestry. p.1-9, 2006.

IAWA Committee (WHEELER, E.A.; BAAS, P.; GASSON, P.E). IAWA list of microscopic features for hardwood identification. IAWA Bulletin, v.10, n. 3, p. 218-359, 1989.

JUDD, W.S.; CAMPBELL, C.S.; KELLOGG, E.A.; STEVENS, P.F.; DONOGHUE, M.J. Sistemática Vegetal: um enfoque filogenético. Porto Alegre: Artmed, 2009. p. 206-224.

LORENZI, H.; SOUZA, H.M.; TORRES, M.A.V.; BACHER, L.B. Árvores exóticas no Brasil: madeiras, ornamentais e aromáticas. Nova Odessa: Instituto Plantarum, 2003. 368 p.

MARCHIORI, J.N.C. Dendrologia das Gimnospermas. Santa Maria: Editora da UFSM, 2005. $191 \mathrm{p}$.

RODIN, R.J. Distribution of Welwitschia mirabilis. American Journal of Botany, n. 40, p. 280-285, 1953.

SOUZA, V.C.; LORENZI, H. Botânica Sistemática: guia ilustrado para identificação das famílias de Angiospermas da flora brasileira, baseado em APG III. Nova Odessa: Instituto Plantarum, 2012. p. 63-71. 